Peter T.-L. Choi MD,

Luis G. Quinonez MD, *

Deborah J. Cook MD FRCPC MSc(EPID), ${ }^{\dagger}$

Fred Baxter MD FRCPC,

Lori Whitehead MD FRCPC ${ }^{\dagger}$

\title{
The use of glycopyrrolate in a case of intermediate syndrome following acute organophosphate poisoning
}

Purpose: This report describes a case of organophosphate intoxication refractory to atropine in which glycopyrrolate was used to reduce cholinergic symptoms, and describes the development of intermediate syndrome, an uncommon subacute complication of organophosphate poisoning.

Clinical features: A 44-yr-old woman presented in cholinergic crisis following malathion ingestion. Treatment was initiated with atropine and pralidoxime. Despite clinical signs of adequate atropinisation, the patient continued to have profuse bronchorrhoea, which resolved with glycopyrrolate. During her course in the intensive care unit, she displayed a subacute deterioration in neuromuscular and mental status with decrement-increment phenomenon on electromyography consistent with intermediate syndrome. The patient eventually made a complete recovery.

Conclusion: This case report describes the successful use of glycopyrrolate in organophosphate intoxication and the development of the intermediate syndrome, characterised by onset of weakness of neck flexors, proximal limb muscles, and respiratory muscles within one to four days after poisoning. Recognition of the syndrome is important in light of the potential for respiratory depression requiring ventilatory support.

Objectif : Cette observation décrit un cas d'intoxication aux organophosphorés réfractaire à l'atropine où le glycopyrrolate a été utilisé pour diminuer les symptômes cholinergiques, et décrit aussi le développement d'un syndrome intermédiaire, une complication subaiguë non fréquente de l'empoisonnement aux organophosphorés.

Éléments cliniques : Une femme de 44 ans se présente en crise cholinergique suite à l'ingestion de malathion. On débute le traitement à l'atropine et à la pralidoxime. Malgré des signes cliniques d'atropinisation adéquate, la patiente continue à présenter une bronchorrhée profuse, qui rentre dans l'ordre avec le glycopyrrolate. Durant son séjour aux soins intensifs, elle présente une détérioration subaiguë de la fonction neuromusculaire et mentale avec phénomène incrémentiel-décrémentiel à l'électromyographie, compatible avec un syndrome intermédiaire. Cette patiente va éventuellement récupérer complètement.

Conclusion : Cette observation à propos d'un cas décrit l'utilisation avec succès du glycopyrrolate dans l'intoxication aux organophosphorés et la survenue d'un syndrome intermédiaire caractérisé par l'apparition de faiblesse au niveau des féchisseurs du cou, des muscles proximaux des membres et des muscles respiratoires survenant dans un délai de un à quatre jours après l'intoxication. Lidentification de ce syndrome est importante à cause de son potentiel d'insuffisance respiratoire nécessitant un support ventilatoire.

From the Departments of Anaesthesia, Surgery, ${ }^{*}$ and Internal Medicine, ${ }^{\dagger}$ McMaster University and St. Joseph's Hospital, Hamilton, Ontario. Dr. Cook is a Career Scientist of the Ontario Ministry of Health.

Address correspondence to: Dr. Peter T. Choi, Department of Anaesthesia, McMaster University, Room HSC-2U1, 1200 Main Street

West, Hamilton, Ontario, Canada L8N 3Z5; Phone: 905-521-2100; Fax 905-523-1224; E-mail: choip@fhs.mcmaster.ca

Accepted for publication January 11,1998 . 
$\mathrm{O}$ RGANOPHOSPHATES are commonly found in agricultural insecticides and irreversibly inhibit acetylcholinesterase ( $\mathrm{AChE}$ ), preventing the cleavage of acetylcholine to acetic acid and choline. Intoxication occurs through absorption from skin or respiratory and gastrointestinal tracts; diagnosis is based on clinical findings and erythrocyte AChE levels. ${ }^{1}$ Symptoms of organophosphate intoxication are those of cholinergic stimulation ${ }^{1,2}$ and delayed neuropsychiatric sequelae including a subacute paralytic syndrome known as the intermediate syndrome. Treatment includes nicotinic antagonism and $\mathrm{AChE}$ reactivation with oximes ${ }^{3}$ and muscarinic antagonism with atropine $^{3}$ and more recently with glycopyrrolate. ${ }^{4-6} \mathrm{We}$ present a case of organophosphate poisoning with intermediate syndrome treated with glycopyrrolate.

\section{Case report}

A 44-yr-old woman was found flaccid with profuse bronchorrhoea four hours after ingestion of $125 \mathrm{ml}$ malathion $\mathbf{5 0 \%}$, an organophosphate insecticide. The trachea was intubated and she was given $1 \mathrm{mg}$ atropine and $2 \mathrm{mg}$ naloxone iv by the paramedics.

In the emergency room, her heart rate was 122 bpm, blood pressure was $138 / 78 \mathrm{mmHg}$, temperature was $35.5^{\circ} \mathrm{C}$, and ventilation was at 12 breaths per min. Her skin was dry. Cardiorespiratory and abdominal examinations were normal. She was alert and responded appropriately by blinking her eyes. Her pupils were unequal, midsize, and sluggishly reactive. Motor examination initially revealed flaccid tone without fasciculations and $3 / 5$ strength in the proximal limb muscles. Except for $1 / 4$ Achilles tendon reflexes, all deep tendon reflexes were absent.

Electrolytes, urea, creatinine, glucose, measured osmolality, haemoglobin, and platelet count were normal. White blood cell count was $21 \times 10^{9} \cdot \mathrm{L}^{-1}$. A screen for acetaminophen, ethanol, salicylates, and tricyclic acids was negative. Erythrocyte AChE activity level was undetectable. Electrocardiogram and chest $\mathrm{x}$-ray were normal.

In the emergency room $50 \mathrm{~g}$ charcoal via nasogastric tube and atropine and pralidoxime ip (Table) were administered. More atropine and charcoal were given in the intensive care unit (ICU). Over the next $48 \mathrm{hr}$ in the ICU she developed a fluctuating level of consciousness, her pupils became pinpoint, gag reflex disappeared, and she was unable to raise her neck and limbs against gravity. Electromyography on day 8 showed a decrement-increment response with repetitive supramaximal ulnar stimulation at 3,10 , and $20 \mathrm{~Hz}$. Profuse bronchorrhoea continued despite evidence of adequate atropinisation (mydriasis, tachycar- dia, anhidrosis) and pralidoxime. She remained ventilator dependent with maximum inspiratory pressure decreased to $-10 \mathrm{~cm} \mathrm{H}_{2} \mathrm{O}$. On day 7 , she developed nosocomial pneumonia, which resolved with broad spectrum antibiotic therapy. Aerosolised ipratropium 8 puffs $\mathrm{q} 4 \mathrm{~h}$ and glycopyrrolate ip (Table) were started; atropine and pralidoxime were discontinued the next day. Glycopyrrolate effectively managed her bronchorrhoea and was discontinued on day 11 . The trachea was extubated on day 13 and she was transferred to a medical ward.

Three days later, she had occasional episodes of confusion, agitation, and visual hallucinations. On day 23, she displayed more agitation, disorientation, fluctuating level of consciousness, visual hallucinations, and somatic delusions. She became aggressive and inappropriate, voiding on the floor and throwing faeces, and was transferred to a psychiatric ward.

All investigations including electroencephalogram and non-contrast computed tomogram of the head were normal aside from a platelet count of $884 \times 10^{9} \cdot \mathrm{L}^{-1}$ and a mildly elevated gamma-glutamyl transferase of $76 \mathrm{U} \cdot \mathrm{L}^{-1}$ (normal 0-30 U. $\mathrm{L}^{-1}$ ). The patient was secluded and treated with oral lorazepam. Her delirium resolved over $48 \mathrm{hr}$ and she returned to the psychiatric ward. She was discharged from hospital on day $\mathbf{3 5}$ in stable condition.

\section{Discussion}

We have presented a case demonstrating acute manifestations of organophosphate poisoning in which glycopyrrolate was required for profuse bronchorrhoea refractory to atropine. Our case also demonstrates findings compatible with intermediate syndrome and organophosphate delirium.

Glycopyrrolate, with its high selectivity for peripheral cholinergic sites, has been suggested as a useful drug in organophosphate intoxication for controlling secretions with minimal side-effects of flushing, tachycardia,

TABLE Drug therapy administered for acute organophosphate poisoning.

\begin{tabular}{llll}
\hline Day & $\begin{array}{l}\text { Atropine } \\
(\mathrm{mg})\end{array}$ & $\begin{array}{l}\text { Glycopyrrolate } \\
(\mathrm{mg})\end{array}$ & $\begin{array}{l}\text { Pralidoxime } \\
(\mathrm{g})\end{array}$ \\
\hline 1 & 4.5 & & 4 \\
2 & 17.0 & & 4 \\
3 & 12.0 & & 4 \\
4 & 4.0 & & 3 \\
5 & 4.0 & & 2 \\
6 & 3.5 & 0.7 & \\
7 & 2.0 & 4.5 & \\
8 & & 2.2 & \\
9 & & 0.8 & \\
10 & & & \\
\hline
\end{tabular}


and depressed level of consciousness often experienced with atropine. ${ }^{4,6}$ Glycopyrrolate has the advantages of better secretion control, less tachycardia, and inability to cross the blood-brain barrier but it is less effective in treating bradycardia and may not affect central neurologic effects from organophosphates. ${ }^{5,6}$ In two cases of organophosphate poisoning, a combination of glycopyrrolate and atropine adequately controlled bronchorrhoea and bradycardia without causing tachycardia. ${ }^{6} \mathrm{~A}$ double-blind randomised trial of 39 patients comparing glycopyrrolate and atropine showed no differences in clinical outcomes and complications. ${ }^{4}$ However, the small sample size precludes exclusion of a Type II error. The use of glycopyrrolate with or without atropine in organophosphate poisoning requires further study.

Within $48 \mathrm{hr}$ of presentation, our patient's muscle strength and mental status deteriorated, consistent with the "intermediate syndrome" which may occur one to four days following the acute cholinergic phase and is characterised by neck and proximal motor weakness, cranial nerve palsies, and respiratory muscle paresis along with depressed or absent tendon reflexes. ${ }^{7,8}$ Repetitive ulnar nerve stimulation with nine supramaximal stimuli at 10 to $50 \mathrm{~Hz}$ recorded over the abductor pollicis brevis results in a decremental response, maximal at the second stimulus, followed by incomplete amplitude recovery (decrement-increment phenomenon) as seen in our patient or complete fade (decrement response)..$^{7-9}$ Post-tetanic facilitation is absent and train-of-four supramaximal stimuli at $2 \mathrm{~Hz}$ results in normal amplitudes. ${ }^{7}$ No definitive treatment has been described but recognition is important since the syndrome carries a risk of death from respiratory failure. Persistent electromyographic abnormalities predicted the need for ongoing ventilatory support in one study. ${ }^{9}$ Normalisation of electromyographic findings occurs two to three days before recovery, which may take five to twenty days. ${ }^{7,8}$ Most patients will not develop delayed polyneuropathy. In one case series, ${ }^{8}$ eight of nineteen patients (42\%) developed intermediate syndrome suggesting that a high index of suspicion is needed to identify this sequela of organophosphate poisoning. The true incidence of intermediate syndrome is unclear since reporting bias confounds available case series evidence.

We believe that our patient developed delirium from organophosphate intoxication three weeks postingestion since no other identifiable organic cause was found. Behavioural symptoms including depression, ${ }^{10,11}$ psychosis, ${ }^{12}$ aggression, ${ }^{13}$ irritability, and memory and concentration problems ${ }^{12}$ have been reported late after organophosphate poisoning. Causation is difficult to demonstrate as most descriptions are case-reports. One case series reported "delirium combativeness" and hallucinations in ten of 190 patients. ${ }^{14}$ The few casecontrol studies available regarding causation of neurobehavioural symptoms by organophosphates ${ }^{15-17}$ show conflicting results.

Aside from acute and subacute neurological symptoms, organophosphate can cause a number of chronic neurological sequelae including a delayed sensorimotor polyneuropathy characterised by predominantly lower limb spasticity and ataxia. Upper limbs are involved in severe cases. Onset occurs two to four weeks postexposure $^{2,8}$ and recovery is slow and often incomplete. ${ }^{2}$ No effective treatment is available. Our patient did not develop this problem.

In summary, this case of organophosphate poisoning describes the successful use of glycopyrrolate, which has the advantage of antimuscarinic activity without the central anticholinergic side effects associated with atropine. Our patient developed the Intermediate Syndrome, an uncommon sequela that occurs shortly after the acute cholinergic phase of intoxication. Recognition is important in light of the associated potential for respiratory depression requiring ventilatory support.

\section{References}

1 Marrs TC. Organophosphate poisoning. Pharmacol Ther 1993; 58: 51-66.

2 Karalliedde L, Senanayake N. Organophosphorus insecticide poisoning. Br J Anaesth 1989; 63: 736-50.

3 Thompson DF, Thompson GD, Greenwood RB, Trammel $H L$. Therapeutic dosing of pralidoxime chloride. Drug Intelligence and Clinical Pharmacy 1987; 21: 590-3.

4 Bardin PG, van Eeden SF. Organophosphate poisoning: grading the severity and comparing treatment between atropine and glycopyrrolate. Crit Care Med 1990; 18: 956-60.

5 Gallagher H, Tracey JA. Organophosphorus insecticide poisoning (Letter). Br J Anaesth 1990; 65: 293-4.

6 Tracey JA, Gallagher $H$. Use of glycopyrrolate and atropine in acute organophosphorus poisoning. Hum Exp Toxicol 1990; 9: 99-100.

7 Senanayake N, Karalleidde L. Neurotoxic effects of organophosphorus insecticides. An intermediate syndrome. N Engl J Med 1987; 316: 761-3.

8 De Bleecker J, Van Den Neucker K, Colardyn F. Intermediate syndrome in organophosphorus poisoning: a prospective study. Crit Care Med 1993; 21: 1706-11.

9 Besser R, Gutmann L, Dillmann U, Weilemann LS, $H o p f H C$. End-plate dysfunction in acute organophosphate intoxication. Neurology 1989; 39: 561-7.

10 Joubert J, Joubert PH. Chorea and psychiatric changes in organophosphate poisoning. A report of 2 further cases. S Afr Med J 1988; 74: 32-4. 
11 Rosenthal NE, Cameron CL. Exaggerated sensitivity to an organophosphate pesticide (Letter). Am J Psychiat 1991; 148: 270.

12 Bowers $M B$ Jr, Goodman E, Sim VM. Some behavioral changes in man following exposure to anticholinesterase administration. J Nerv Ment Dis 1964; 138: 383-9.

13 Devinsky O, Kernan J, Bear DM. Aggressive behavior following exposure to cholinesterase inhibitors. J Neuropsychiat Clin Neurosci 1992; 4: 189-94.

14 Agarwal SB. A clinical, biochemical, neurobehavioral, and sociopsychological study of 190 patients admitted to hospital as a result of acute organophosphorus poisoning. Environ Res 1993; 62: 63-70.

15 Rodnitzky RL, Levin HS, Mick DL. Occupational exposure to organophosphate pesticides. A neurobehavioral study. Arch Environ Health 1975; 30: 98-103.

16 Savage EP, Keefe TJ, Mounce LM, Heaton RK, Lewis $J A$, Burcar PJ. Chronic neurological sequelae of acute organophosphate pesticide poisoning. Arch Environ Health $1988 ; 43: 38-45$.

17 Rosenstock L, Keifer M, Daniell WE, McConnell R, Claypoole $K$, and the Pesticide Health Effects Study Group. Chronic central nervous system effects of acute organophosphate pesticide intoxication. Lancet 1991; 338: 223-7. 